\title{
CONCEPTUAL DESIGN OF INJECTION MOULD TOOL FOR MAIN BODY PART OF AN AIR INFLATOR
}

\author{
H M D Faziur Rehaman ${ }^{1}$, Hemanth $\mathbf{R}^{2}$ \\ ${ }^{1}$ Student. Dept. of PG studies, Govt. Tool Room \& Training centre, Mysore-570016 \\ ${ }^{2}$ Lecturer. Dept. of PG studies, Govt. Tool Room \& Training centre, Mysore-570016
}

\begin{abstract}
This paper presents the conceptual design of plastic injection mould for Main body of an air inflator, which is used for air filling in the dunnage bags. The fundamental aim of the designer is to achieve balance between productivity and design, by optimizing the design, process and manufacturing parameters, which results in the final cost reduction of the mouldings without compromising the quality of the product. The various parameters like processing temperature, pressure, melt velocity, filling time, moulding material, parting line selection, feed system, mould cooling, ejection system, etc. affects the design of mould and its functions with variation in cost and quality for producing optimized quality mouldings. By varying some of the above said parameters an effort is made to attain a cost effective conceptual design. The suggested material for Main body of an air inflator is polyamide 66. Designing of mould is carried out by using computer aided designing software Unigraphic.
\end{abstract}

Keywords: Injection moulding, two plate mould design, polyamide 66, hot runner system.

\section{INTRODUCTION}

The plastic products manufacturing industry has been growing very rapidly in recent years. This growth will be accelerated by the tendency to substitute plastics for metal, which is appearing throughout the world. The injection moulding process is the most popular moulding process for making thermoplastic parts. The conceptual design of an injection moulding part is a highly iterative process. It involves a practical knowledge component about areas of customer needs, part design requirements, material selection, and mold design features, mold making processes, moulding equipment and production economics. The injection moulding process requires the use of an injection moulding machine, raw plastic material, and a mold. The plastic is melted in the injection moulding machine and then injected into the mold, where it cools and solidifies into the final part [1].

\section{INJECTION MOLDING CYCLE}

The moulding cycle Fig.1 starts with the retraction of the ejector plate, followed by closing of the mold. The injection unit melts the polymer resin and injects the polymer melt into the mold. The ram fed injection moulding machine uses a hydraulically operated plunger to push the plastic through a heated region. The melt converges at a nozzle and is injected into the mold. The melt is forced into the mold in two or three stages.

Typical cycle times range from 10 to 100 seconds and are controlled by the cooling time of the thermoplastic or curing time of the thermosetting plastic material [2].

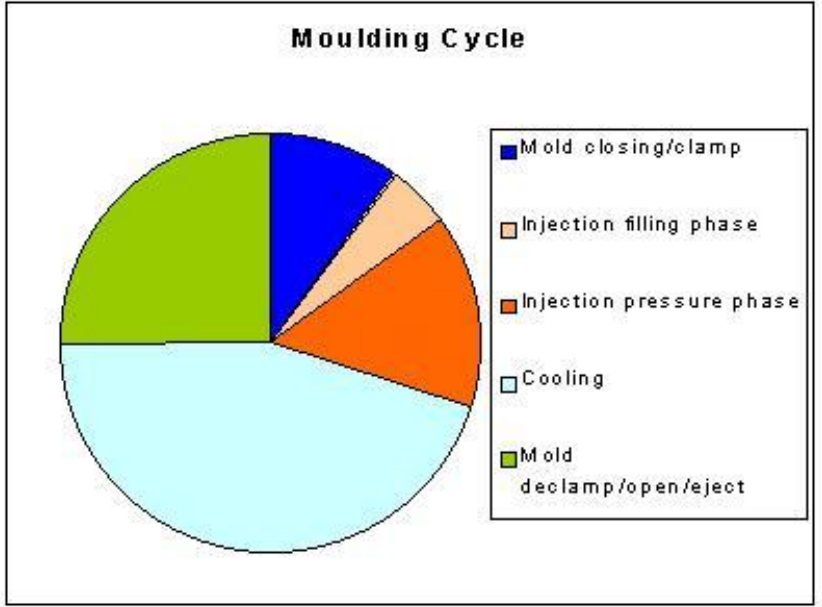

Fig 1: Injection moulding cycle [reference]

- Mould close and clamp, (few seconds depends on machine speeds)

- Injection Fill (speed) phase, (few seconds)

- Switchover and Pack (pressure)phase,(few seconds)

- Cooling time (40 to $60 \%$ of cycle time)

\section{METHODOLOGY}

Components are modeled using the CADD software Unigraphic 8.0. Component has a Hallow cylindrical structure with dimensions: OD $57.16 \mathrm{~mm}$, ID 22.66 and length $197 \mathrm{~mm}$ as a moulded part was used. Component has few bosses, under 
cuts and ribs as shown in the figure and other details of model are given below

Component Name: Main body part

Material: polyamide 66 (Zytal)

Shrinkage: $1.8-2 \%$

Moulding type: Single Cavity injection mould tool

Tonnage required: 200 tonnage capacity

Density: $1.08 \mathrm{~g} / \mathrm{cm}^{3}$

Projected area of component: $111.592 \mathrm{~cm}^{2}$ (From CAD Model)

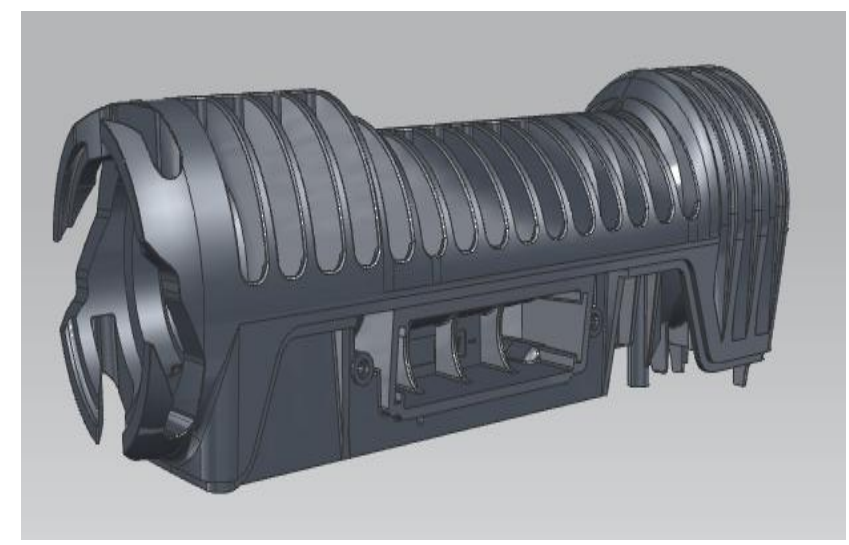

Fig 2: 3D Model of component

There are two basic categories of plastic injection moulding: thermoplastic and thermoset. PA66 (Polyamide 66) ZYTAL ST801AWNCO10 is utilizing for the production of component. ZYTAL ST801AWNCO10 is specially used because of its super tough property. It is achieve important properties include high tensile and flexural strength, stiffness, excellent heat deflection temperature, and superior abrasion and wear resistance but moister greatly affects the properties of material, if storage container is opened, it is recommended that $85 \mathrm{C}$ hot air for drying, if humidity is greater than $0.2 \%$ still need to be $105 \mathrm{C}$ for 12 hours of vacuum drying [3].

Heating of material PA6/6 should not exceed more than $300 \mathrm{C}$ to avoid degrading of the material, this can be controlled by providing heat sensor and controlling the heat supply, fig. 2 shows the 3D model of Main body part of an air inflator.

Model study includes identifying the criticality in component; following are the criticality involved in component.

- Require side cores

- Proper ejection method required to eject component because of using side cores

- Few undercuts, ribs, bosses and text on rear side

- Part is of $156 \mathrm{~g}$

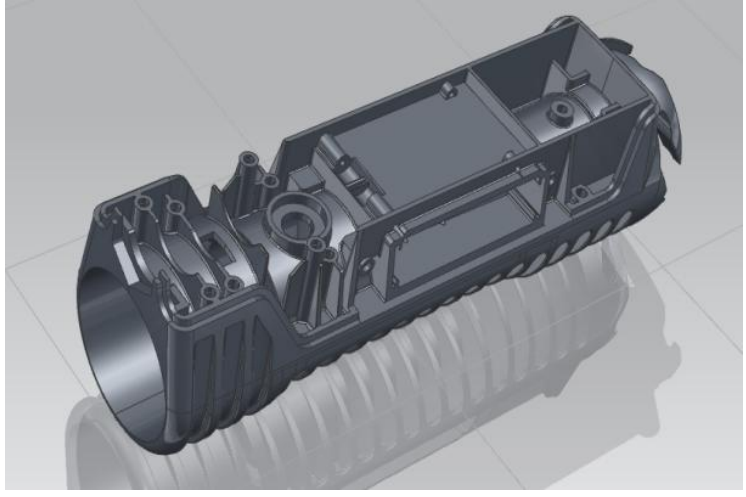

Fig 3: Complexity in Component

\section{BASIC DESIGN OF INJECTION MOLD TOOL}

The main objective of the conceptual design is to enable the design engineer to create the injection mold design feature quickly, according to the product requirement and plastic material characteristic.

Three design concepts had been considered in designing of the mould including

1. Two-Plate Mould (concept 1) with single cavity. Locating the components parallel to the machine axis. Not applicable due to ejection and injection problem because the length of part is $197 \mathrm{~mm}$, will make a deep impression into cavity halves and also restriction with geometry of the part.

2. Two-Plate mould (concept2) with single cavity and actuation is by hydraulic system, part to incline to machine axis.

Not applicable due to higher cost of hydraulic system and inclination will also affect the ejection of the part.

3. Two-Plate mould (concept 3) single cavity with both hydraulic and finger cam actuated and part locating perpendicular to the machine axis.

In designing of the mould for main body part, the third design concept had been applied. Various design considerations had been applied in the design. The mold designed based on the platen demission of the plastic injection machine used. There is a limitation of the machine, which is the maximum area of machine platen, is given by the distance between two tie bars i.e. in both $\mathrm{X}$ and $\mathrm{Y}$ direction is limited to $600 \mathrm{~mm}$. Therefore the maximum width of the mould plate should not exceed the distance.

Factors to be considered during design of any moulding tool

- Design and material of components

- Number of components required

- Selection of Injection moulding machine

- Number of cavities 
- Type of tool

- Selection of parting line

- Positioning of core and cavity

- Ejection system

- Designing of layout

- Fool proofing arrangements

- Cooling elements

- Tool life

All above factors has to be considered during the designing which affects directly or indirectly. In order to control the processing temperature, pressure, melt velocity, filling time, moulding material, parting line selection, feed system, mould cooling, ejection system, etc by proper consideration of the factors greater control over the process and process parameters can be obtained.

\section{TWO PLATE MOLD CONCEPT}

The two plate mold is simple and most reliable. It consists of moving and stationary half. The cavity and core can be mounted on the either half, depending upon the part design and location of knock out pin. This mold adapted easily for different design and all parts ejection method.

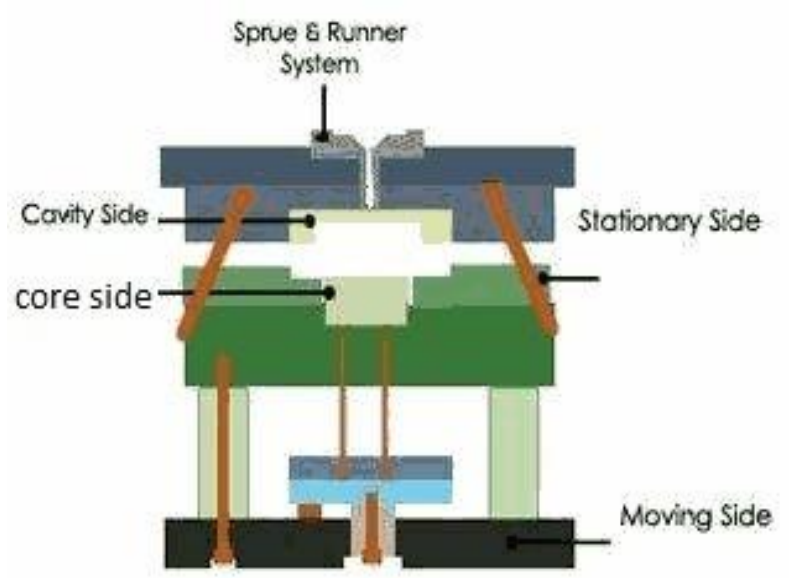

Sider Mold

Fig 4: Standard two plate mold

This consists of two halves fastened to the two platens of the moulding machine's clamping unit. When the clamping unit is opened, the mold halves separate. The parting surface is the surface shared by the two mold halves.

A cooling system is required for the mold. This consists of an external pump connected to passageways in the mold, through which water is circulated to remove heat from the hot plastic [4].

\subsection{Core and Cavity}

Core and Cavity are formed when mold is separated into two halves, which permit the part to be extracted. In general the orientation and shape of part must not cause to be blocked into the mold.

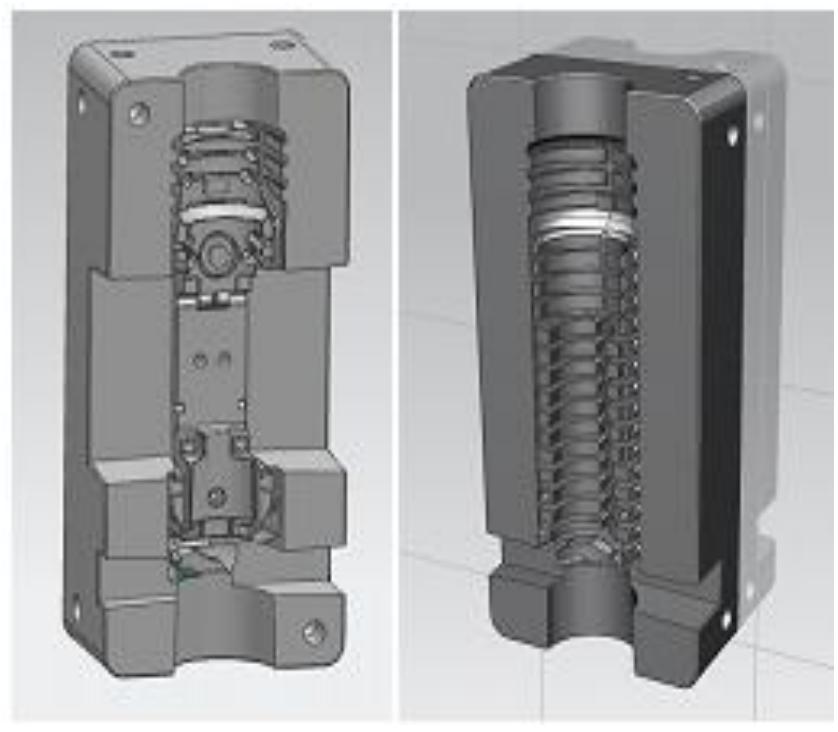

Fig 5: Core and Cavity [references]

\subsection{Feed System}

\subsubsection{Hot Runner Design}

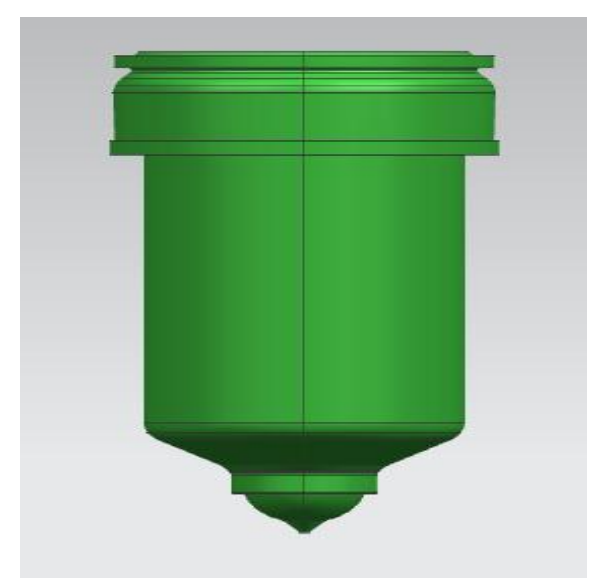

Fig 6: Hot runner system [references]

The hot runner system accommodates the molten plastic material coming from the barrel and guides it into the mold cavity. A hot sprue bush is to be incorporated with the tool.

Hot runner usually makes the mold more expensive to manufacture and run but allow saving by reducing the plastic waste and by reducing the cycle time [5]. 


\section{Benefits of a Hot Runner System}

- Reduces cycle times.

- Eliminates the cold runner that would be either scrap or require regrind.

- Improves part consistency and quality.

- Reduced gate mark.

- Reduces injection pressure.

- Increased process control for fine tuning of mold and part.

\subsubsection{Gate}

A small opening which connects the runner and cavity is called as gate. As shown in fig 6, the gate is of pin point, leaving a very negligible mark on the surface of the component. When designing an injection mold the size and location of the gate is one of the most important considerations for correct moulding of the part. Incorrect gate positioning can result in uneven filling, over packing, and dimensional instability of the part. Incorrect selection of the gate size can result in an inability to fill the part, inability to thermally shut off the gate, dimensional instability or internal stresses in the part.

The most common gate type is direct pin point gating, which offers the simplest construction and high reliability.

\subsubsection{Ejection System}

An ejection is very much necessary in order to eject the moulded part from the tool. The design of ejection system is one of the major factors, how efficiently the tool will be in production. The cavity is divided in two mold halves in such a way that natural shrinkage of moulding causes the part to stick moving half when mold open, ejector pin pushes the part out of the tool.

The component is ejected positively without exhibiting any tendency to twist, distort or hang back. In general mould release is hindered by shrinkage of the part on mold cores. Large ejection areas uniformly distributed over the molding are advised to avoid deformations [5].

\section{Ejector systems used in this tool}

- Ejector pin

- profile ejector pin

When no special ejection problems are expected, the standard ejector pin will perform well. In this case for cylindrical parts like bosses a sleeve ejector is used to provide uniform ejection around the core pin.

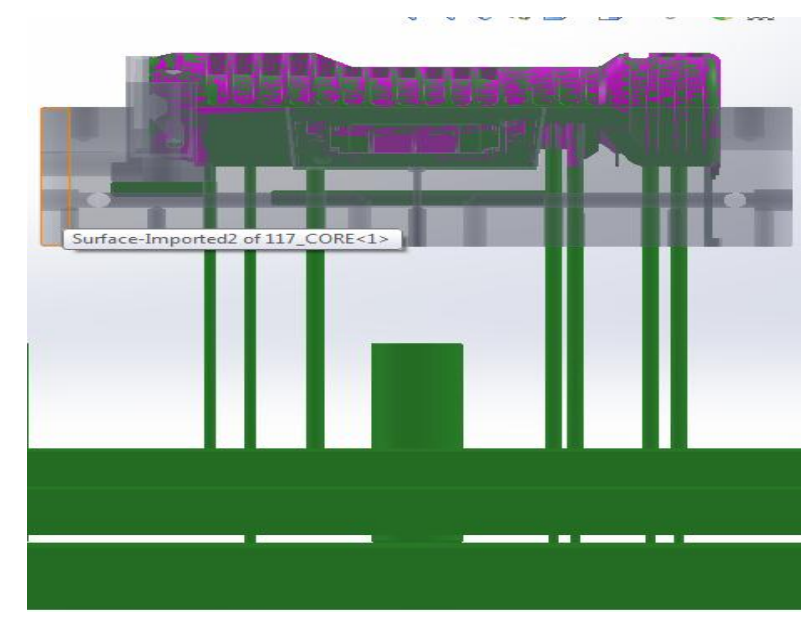

Fig 7: Ejection system [references]

\section{CONCLUSIONS}

The work, deals with the Concept of designing of an injection mould tool for main body part for an air inflator. The TwoPlate mould design with hot runner system will make it possible to produce high quality product at considerable cost. By proper supply of heat and temperature will overcome the effects on the part being produced. The final product will be produced with less number of defects almost like a finished product.

\section{REFERENCES}

[1] Knowledge-based Evaluation for the Conceptual Design Development of Injection MoldingPartsKWAISANG CHINCity University of Hong Kong, Hong Kong

[2] Osswald, T., Sheng, L., Gramann, P.J., Injection Molding Handbook. Munich.Hansner (2002).

[3] International Journal of Engineering, Science and Technology Vol. 2, No. 2, 2010, pp. 13-22

[4] Injection Mould Design, R.G.W. Pai

[5] Technical Directory on Design and Tooling for Plastics, CIPET 